\section{Rapid Flowering of Microcultured Cranberry Plants}

\author{
Rodney Serres and Brent McCown \\ Department of Horticulture, University of Wisconsin-Madison, Madison, \\ WI 53706
}

Additional index words. Vaccinium macrocarpon, paclobutrazol, gibberellic acid, flower bud induction, growth retardant

\begin{abstract}
The capability to uniformlyinduce flowering in cranberry(Vaccinium macrocarpon Ait. 'Stevens') in < 1 year from microculture was investigated to accelerate cranberry breeding and to study woody plant reproductive biotechnology. Flower buds were induced on newly micropropagated cranberry plants during the first growing season. A treatment of $2.5 \mathrm{mg}$ of paclobutrazol applied as a soil drench per 2- to 3-month-old potted plant in midsummer, when the plants were grown in coldframes under natural daylength and air temperatures, resulted in $\mathbf{7 0 \%}$ of the plants flowering. Plants not treated with paclobutrazol did not flower. Reduced but significant flower bud set was observed on plants treated with paclobutrazol but grown in the greenhouse under natural daylength. Flowering was stimulated by cold treatment coupled with gibberellin sprays and/or repotting to nonpaclobutrazol-treated medium. Chemical name used: $\beta$-[(4-chlorophenyl)methyl]-ct(1,1-dimethylethyl)-1H-1,2,4-triazole-1-ethanol (paclobutrazol).
\end{abstract}

Cranberry is a vegetatively propagated perennial fruit crop cultivated in cool climates and lowland areas. Flowering occurs in early spring at the base of new growth of upright stems. Flower bud induction for the following year normally occurs in mid-summer (Mainland, 1985). Mixed vegetative/reproductive terminal buds are evident by fall on flowering uprights. Rapidly growing horizontal runners normally do not set flower buds.

As is the case with most woody perennials, cranberry seedlings have an extended juvenile period. Seedlings produce vigorous vegetative growth (mostly runners) their first 2 years; during the second growing season, flower buds may be induced at the terminals of new upright stems, resulting in flowering during the spring of the third growing season. Microcultured cranberry plants act physiologically similar to seedlings in that they also produce mainly runners during their first season and thus do not produce flowers until their third growing season. In contrast, traditional cuttings from mature cranberry plants, such as is used for establishing new cranberry beds, maintain upright and runner growth and thus often set flower buds the same season they are propagated.

In this study, we investigated the use of paclobutrazol treatments to reduce the time required for microcultured cranberry plants to

\footnotetext{
Received for publication 24 Aug. 1993. Accepted for publication 13 Oct. 1993. We appreciate the technical help of Eric Zeldin and Heidi Heel. This research was supported by the Wisconsin Cranberry Board and the Agricultural Research Station, College of Agriculture and Life Sciences, Univ. of Wisconsin-Madison. Mention of trade names is for the convenience of the reader and does not constitute endorsement by the Univ. of Wisconsin. The cost of publishing this paper was defrayed in part by the payment of page charges. Under postal regulations, this paper therefore must be hereby marked advertisement solely to indicate this fact.
}

flower, thus accelerating cranberry breeding programs that require sexual crosses or analyses of gene expression in reproductive tissues. The growth regulator, paclobutrazol, was applied to cranberry plants in an attempt to inhibit vigorous vegetative growth and promote flower bud development. These responses are typically seen when growth retardants are applied to other Ericaceous plants (Stuart, 1975). Reduction of internode length and the production of compact, bushy plants with paclobutrazol treatment have been reported for herbaceous flowering plants (Cox and Keever, 1988) and woody perennials (Looney and McKellar, 1987) and is the result of inhibition of gibberellin biosynthesis (Steffens et al., 1985). Paclobutrazol has been applied to field-collected, cutting-derived cranberry plants to reduce runner growth and was found to produce a high percentage of buds with flowers (McArthur and Eaton, 1989).

\section{Materials and Methods}

'Stevens' cranberry shoot cultures were maintained for $>2$ years on woody plant medium (Lloyd and McCown, 1972) containing $0.1 \mu \mathrm{M} \mathrm{N}^{6}$-[2-isopentenyl] adenine(2ip), $0.13 \%$ D-gluconic acid (calcium gluconate), $0.3 \%$ agar (Sigma, St. Louis), 0.170 Gelrite (Scott, Fiskeville, R.I.), and 2\% sucrose. In May of each of two subsequent years, rooted shoots were removed from the culture vessels and placed in plasticized peat plugs (Grow-Tech, Watsonville, Calif.) for continued root growth and acclimation to laboratory humidity levels.

After 3 weeks, the plants were moved to the greenhouse where they were potted in a peat: perlite mixture in $9 \times 9 \times 7$-cm square plastic pots. Miracid fertilizer (30N-10P-10K) (Stem's, Port Washington, N.Y.) was applied at $2.5 \mathrm{~g} \cdot$ liter $^{-1}$ weekly for 4 weeks. Three weeks after being moved to the greenhouse, half of the plants were treated with a $100-\mathrm{ml}$ soil drench of $25 \mathrm{mg}$ paclobutrazol/liter water, and the remaining plants were drenched with a water control. The two treatments were separated by placing the pots on separate but adjacent carts to prevent possible contamination of nontreated pots by the paclobutrazol.

After 4 weeks in the greenhouse (mid-July), half of the plants of both treatments (paclobutrazol and no paclobutrazol) were selected randomly and moved outside. The pots outside were buried in sandy soil to $2 \mathrm{~cm}$ below the top of the pots to stabilize the pots and prevent overheating of the small volume of medium. All pots within a treatment were placed together, but the two treatments were side by side within an uncovered coldframe. Plants in the greenhouse and the coldframe were fertilized with Peter's Conifer Finisher (4N-25P-35K) (Grace-Sierra, Richardson, Texas) biweekly throughout the summer and autumn. Each of the four treatments consisted of 10 plants.

A total of 40 plants, 10 plants per treatment, was used in the first-year study. In the second year, 30 additional cranberry plants were potted and grown in the greenhouse. These plants were treated with paclobutrazol at 6,10 , or 14 weeks after potting and moved to the coldframe in late July, late August, and late September, respectively.

The average air minimum in the coldframes was 14.5 and $12.9 \mathrm{C}$ for July and 13.2 and 10.0C for August in 1991 and 1992, respectively. The greenhouse was fan-and-pad-cooled and lightly shaded; the minimum night air temperature was set at $15 \mathrm{C}$.

In late October, all plants were removed from the greenhouse and coldframe and placed in a dark cold room at $8 \pm 4 \mathrm{C}$. The pots were kept in trays within plastic bags to prevent excessive drying. In January, the plants were taken to the greenhouse and randomly placed on a bench under 24-h supplemental lighting to increase the photoperiod and light intensity. Five weeks after being in the greenhouse, a gibberellic acid $\left(\mathrm{GA}_{3}\right)$ solution at $50 \mathrm{mg} \cdot \mathrm{liter}^{-1}$ (with two drops of liquid soap/liter to act as a surfactant) was sprayed on the foliage of all plants until dripping to overcome the effects of the paclobutrazol. Plants were scored for the presence of flowers within 3 weeks of the $\mathrm{GA}_{3}$ treatment.

\section{Results and Discussion}

The effects of paclobutrazol were noticeable on the cranberry plants within 2 weeks after application. While nontreated plants continued to grow as vigorous juvenile runners with relatively long internodes, the apical tips of all the shoots on the treated plants were highly compressed, forming a tight rosette of well-developed leaves (Fig. 1). Additionally, more axillary shoots developed on the paclobutrazol-treated plants than on the nontreated plants. These axillary shoots flushed but produced only $\approx 5$-mm-long stems with a rosette of dark-green leaves. Root development of the treated plants appeared to be enhanced, with increased branching and greater overall growth. 


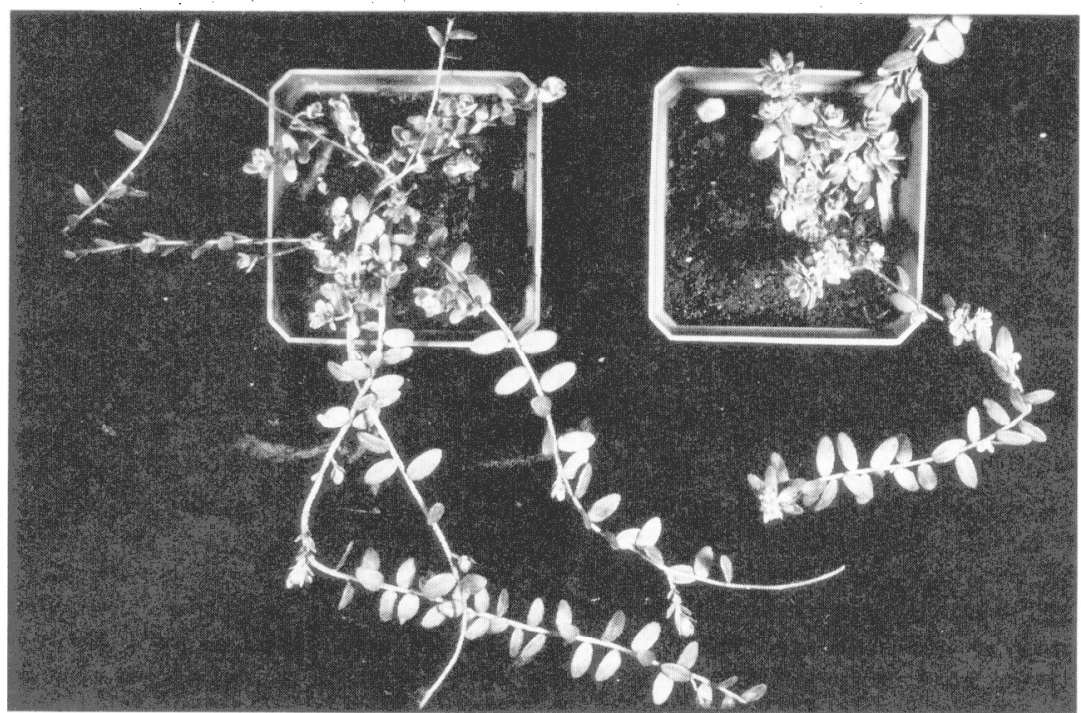

Fig. 1. Effect of a paclobutrazol soil drench on growth of microcultured cranberry plants. The plant on the right was treated with $2.5 \mathrm{mg}$ of paclobutrazol while the plant on the left was not. Plants were photographed at the end of one growing season.

Paclobutrazol-treated plants in the greenhouse had less vegetative growth throughout the summer and autumn, and they appeared to have swollen apical buds on the main stem and branches when moved to the cold room. Nontreated plants in the greenhouse continued active growth through autumn and until they were placed in the cold room. Paclobutrazoltreated plants in the coldframe stopped leaf production by early August when swollen buds with developing bud scales were evident. Nontreated plants in the coldframe continued vegetative growth well into September.

Within 2 weeks after the plants were taken from SC in January, the nontreatedplants from the greenhouse and the coldframe flushed with runner-type growth but did not produce flowers. None of the paclobutrazol-treated plants from either the greenhouse or the coldframe flushed into rapid growth after being removed from the cold room. The well-developed buds visibly enlarged but only partially opened. Within 5 days after the application of a GA spray, however, the buds flushed into uprightlike growth, and flowers opened (Fig. 2). The flowers were hand-pollinated and fruit ripened through the spring, but the fruit produced on these $\mathrm{GA}_{3}$-treated shoots produced very few viable seeds. $\mathrm{GA}_{3}$ applied to plants not treated with paclobutrazol did not affect the growth characteristics of those plants.

All of the paclobutrazol-treated plants grown under coldframe conditions from the 1991 trial produced flowers. In the 1992 trial, four paclobutrazol treatments were applied under coldframe conditions: plants treated with paclobutrazol in mid-July, late July, late August, and late September. The percentages of plants that produced flowers from these treatments were $70 \%, 100 \%, 60 \%$, and $0 \%$, respectively. The July treatments were particularly effective, which agrees with the report that flower bud induction in the field occurs in July in Wisconsin (Roberts and Struckmeyer, 1943).

Plants treated with paclobutrazol in late
September and then moved to the coldframe produced little additional growth, apparently due to the lower air temperatures and shorter days, and did not produce flower buds.

None of the paclobutrazol-treated plants grown only in the greenhouse produced flowers in the 1991 trial, but $30 \%$ of the plants in that treatment produced flowers in the 1992 trial. Although these plants were exposed to the natural daylength, day and night air temperatures were higher than outdoors. These higher air temperatures may have been important in inhibiting flower bud induction or development in this temperate-zone plant. Whether flower bud set can be induced under growth-chamber conditions that simulate the summer-to-fall transition is not known.

Applications of $\mathrm{GA}_{3}$ commonly result in parthenocarpic fruit production (Pharis and King, 1985). Parthenocarpic fruit would defeat the purpose of early flowering for breed- ing and most gene expression and inheritance studies. To eliminate the need for $\mathrm{GA}_{3}$, the paclobutrazol-treated plants can be repotted to fresh medium immediately after bringing them from the cold room, removing as much of the treated medium as possible. Preliminary studies indicate that this results in a more normal shoot flush and fertile flowers (Fig. 3).

Using paclobutrazol in conjunction with natural photoperiod and greenhouse forcing allowed the production of flowers from microcultured plants in 9 months. Without using paclobutrazol or a similar growth retardant, two additional growing seasons may be necessary to produce a high percentage of flowering plants.

Almost certainly, the 9 months used in this study to produce flowering plants could be decreased to $\approx 7$ months to take time by moving the plants to $\approx 8 \mathrm{C}$ early in the autumn (midSeptember) and reducing the amount of time in the cold room to break flower bud dormancy. In this study, plants were held below $12 \mathrm{C}$ for $>1600$ h. Rigby and Dana (1972) report that the dormancy requirement for cranberry is $600 \mathrm{~h}$ below 7C, and Eady and Eaton (1969) report a dormancy requirement of 650 $h$. Thus, the time spent in dormancy after flower bud induction may be reduced to at least one-half that used in our study.

The ability of young cranberry propagules to uniformly flower in $<1$ year provides a unique example for a woody temperate fruit crop. This characteristic, combined with the plant's small mature size, ease of microculture (Scorza and Welker, 1988), and proven receptiveness to genetic engineering (Serres et al., 1992), makes cranberry an interesting model system to consider for studies related to temperate fruit physiology, development, and biotechnology.

\section{Literature Cited}

Cox, D.A. and G.J. Keever. 1988. Paclobutrazol inhibits growth of zinnia and geranium. HortScience 23:1029-1030.

Eady, F. and G.W. Eaton. 1969. Reduced chilling

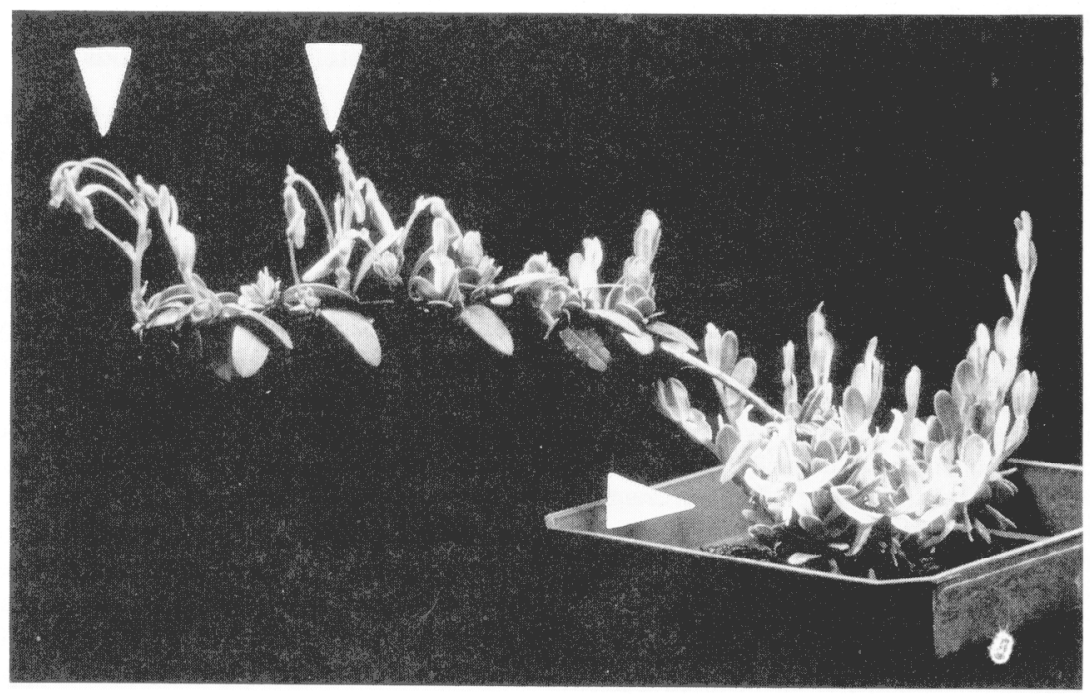

Fig. 2. Flowering of a microcultured cranberry plant 9 months from culture and after treatment with paclobutrazol and $\mathrm{GA}_{3}$. Arrows indicate flowers or flowering uprights. 


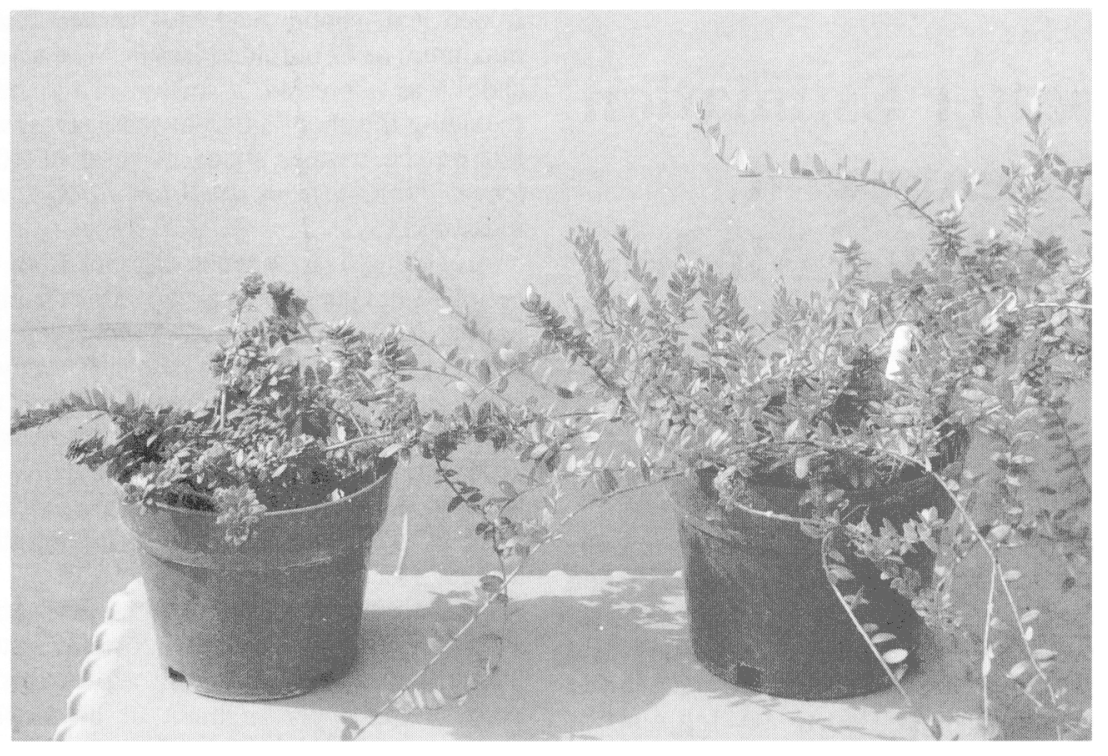

Fig. 3. (right) Resumption of normal growth of a paclobutrazol-treated plant after repotting with fresh medium and (left) continued inhibition by paclobutrazol, after 23 months, when not repotted.

requirement of McFarlin cranberry buds. Can. J. Plant Sci. 49:637-638.

Lloyd, G. and B. McCown. 1972. Commercially feasible micropropagation of mountain laure (Kalmia latifolia) by use of shoot tip culture. Proc. Intl. Plant Prop. Soc. 30421427.
Looney, N.E. and J.E. McKellar. 1987. Effect of foliar-applied and surface-applied paclobutrazol on vegetative growth and fruit quality of sweet cherries. J. Amer. Soc. Hort. Sci. 112:71-76.

Mainland, C.M. 1985. Vaccinium,p.451455. In:
A.H. Halevy (ed.). CRC handbook of flowering. vol. IV. CRC, Boca Raton, Fla.

McArthur, D.A.J. and G.W. Eaton. 1989. Cranberry growth and yield response to fertilizer and paclobutrazol. Scientia Hort. 38:131-146.

Pharis, R.P. and R.W. King. 1985. Gibberellins and reproductive development of seed plants. Annu. Rev. Plant Physiol. 36:517-568.

Rigby, B. and M.N. Dana. 1972. Rest period and flower development in cranberry. J. Amer. Soc. Hort. Sci. 97:145-148.

Roberts, R.H. and B.E. Struckmeyer. 1943. Blossom induction in cranberry. Plant Physiol. 18:534-536.

Scorza, R. and W.V. Welker, Jr. 1988. Cranberries (Vaccinium macrocarpon Ait.), p. 199-208. In Y.P.S. Bajaj (cd.). Biotechnology in agriculture and forestry. vol. 6. Crops II. Springer-Verlag, New York.

Serres, R., E. Stang, D. McCabe, D. Russell, D. Mahr, and B. McCown. 1992. Gene transfer using electric discharge particle bombardment and recovery of transformed cranberry plants. J. Amer. Soc. Hort. Sci. 117(1):174-180.

Steffens, G.L., J.K. Byun, and S.Y. Wang. 1985. Controlling plant growth via the gibberellin biosynthesis system: I. Growth parameter alterations in apple seedlings. Physiol. Plant. 63:163168

Stuart, N.W. 1975. Chemical control of growth and flowering, p. 62-72. In A.M. Kofranek and R.A. Larson (eds.). Growing azaleas commercially. Publ. 4058 Univ. of California Coop. Ext., Davis. 